\title{
Problems should be Paid Attention to on the Maintenance of the Equipment in the College Voice Room
}

\author{
Fan Yun \\ Tianjin Maritime College
}

\begin{abstract}
Keywords: Voice room; Equipment overhaul; Equipment maintenance; Equipment management; Efficient management
\end{abstract}

\begin{abstract}
The current national college speech equipment are carried out in-depth reform, which means pronunciation teaching plays a very important role in language education in College, but in the equipment management process, how to properly maintain and repair to ensure the normal teaching is very important. In this paper pays attention to the discussion of the problems on the maintenance of the equipment of the voice room in Colleges, and draw the conclusion.
\end{abstract}

\section{Introduction}

At present, the task of voice room has become more and more with the reform of language education in China, some English majors and university courses, public hearing industrial and commercial personnel abroad alternative listening test, the National Public English test are needed for the voice room, in short, voice room currently plays an important role in foreign language teaching. Under the existing conditions, according to the actual investigation and study, combined with their own work experience, carries on the discussion to the present college voice room problems, and conclude views on equipment maintenance in voice room.

\section{Problems on the Management and Maintenance of the Voice Room}

There are many problems on the management and maintenance of the voice room. On the students' level, the problems are: (1)Students do not seat on the table in accordance with the provisions of the teacher, and random graffiti affecting the overall order of the class and the desk; (2) Carrying the casual snacks into the classroom and polluting the teaching environment; (3) Students do not cherish public property, and individual students intentionally damage equipment, such as the first headset microphone is broken; (4)Students do not understand how to use the equipment, and the free operation causes damage to the equipment.

From the teacher's perspective, there are the following problems: (1) Part of the teachers have no skilled operation, and the misoperation causes equipment failure; (2)Bring their own disk, $U$ disk installed on the Internet to download information and did not pay attention to the safety operation on the computer, causing the virus; (3) At the end of teaching, teachers don't turn off the power of the computer used causing damage to the equipment; (4) teachers do not use voice classroom and take it as a multimedia classroom which means the function is not sufficient; (5)The lack of classroom ability to guide students to simple troubleshooting of equipment.

From its own perspective, summed up the following problems: (1)The student terminal equipment line easy to exist the problem of bad contact affecting the normal use; (2)Poor stability of master computer teachers; (3)The audio power amplifier equipment is not clear, murmur, hum and other issues; (4) Tape machine's self fault; (5)Teachers' fault recorder; (6)The computer virus leads to un-normal use; (7) CD-ROM fault; (8)Monitor can not display the content of teaching; (9)Fault voice communication system, and the students can talk to each other.

Any of the above problems will affect the process of teaching, and it will lead to that the voice room can not meet the needs of teaching. Therefore, we need to regulate a scientific voice room management method to manage and maintain the voice room equipment. Through years of practice and learning experience, summed up a set of scientific management methods, put forward the following suggestions. 


\section{Scientific Management Countermeasure of Voice Room}

Different management strategies are proposed at different levels:

(1)Student management level: by way of education to improve students self accomplishment, such as caring for public property, no littering, no spitting, no free operation of main control equipment, damaged headset can make relevant voice room rules and regulations, standardize their behavior when using voice room play a role in certain constraints. The provisions can not be zero into voice room, no graffiti, vandalism and other involuntary. The students need to check the corresponding headset and other equipments are in good condition before class, and the desk should be clean and tidy, if you find yourself location problems should be promptly reported to the teacher, the teacher is good to make corresponding countermeasures and equipment damage recording. It needs to make a corresponding punishment to serious damage to the equipment according to the actual situation. But the equipment daily management mainly from the students' mechanical system and take good care of public property, management does not make students genuinely caring for public property, it only through the teachers' teaching and cultivating students' sense of ownership can really do a good job on equipment management.

(2)The level of teacher management: teachers should improve their own operating proficiency of the use of voice room equipment with reasonable and correct operation.

When using the $\mathrm{CD}$ and download files, pay attention to the file non-toxic, so as not to cause paralysis of computer systems. Teachers should develop the habit of closing the computer and the total power supply. The use of voice room should follow the corresponding rules and regulations, each use should be registered, and close the doors and windows after teaching. Schools should regularly arrange technical training for teachers about how to use voice room, so that teachers can promptly understand and familiar with the correct operation of the voice room mode. The purpose of training is to fully understand the function and usage of equipments, strengthen their information literacy ceaselessly, enhance individual open teaching to improve the effect of classroom teaching, and teachers should do practical, concise, truly work to teach students with knowledge in multimedia courseware on improving learning efficiency.

(3) Voice room technical staff level: voice room managers must constantly improve the quality of business with professional and common sense knowledge and education, but also have certain ability to repair, maintenance the equipment in voice room to deal with all kinds of fault equipment to ensure the equipment in good condition. In addition, the technical staff should also do a good job of material management, including copy, software installation, listening material download, tape recording and other aspects of the work. In addition to enhance their own professional literacy, but also to understand the actual needs of teaching, according to the actual teaching situation of teachers to provide material information, and actively cooperate with the teacher's education. At the same time, it should formulate a reasonable training plan to improve the ability of business, there are plans to arrange for them to participate in seminars, meetings, visits, mobilize the enthusiasm of their work improving the overall mechanism, and equally treat their academic promotion, training, allowances and other opportunities to improve their work enthusiasm and the work efficiency.

\section{Solutions to Common Equipment Problems}

About bad contact equipment wire which will lead to some common problems, such as the sound of students headset from time to time, this phenomenon is mostly due to improper plug and host headset connection, and the specific solution is to use WD-40 contact clean lubricant cleaning connection, and then re-inserted into the headset plug, if this method cannot solve the problem, users can replace the headset. When the master control of the teacher is not controlled, and if the operation caused by improper operation of the main control part of the crash, users can press the reset button to restart the computer to restore its function. Users can replace the rectifier diode, electrolytic capacitor voltage, the same capacity to AC sound and noise, and users must pay attention to the positive and negative connections, so that equipment shielding function is good to solve the noise problem of equipment. The timely replacement of belt and tire pressure can solve 
tape recorder machine problems. The solution to the CD-ROM fault is to clean the laser head or to replace the laser head. Display troubles include the common problems are blurred image, color, image appear dark or dark side, there is a drag on the screen, and the image is not stable. Specific measures to solve these problems are: to solve the problem of blurred image with alcohol cleaning tube; replacement of triode video amplifier circuit tube, then re-adjust the color balance potentiometer; rinse with alcohol or directly replace the potentiometer that can solve the problem of unstable color; the other two problems can be solved with the deflection and failure the coil and the tube through the examination of $180 \mathrm{~V}$ filter capacitor.

\section{Conclusion}

Digital teaching is a trend of modern teaching means, and it is also an important symbol of the modernization of foreign language teaching. The great development of information technology provides a powerful guarantee for the development of education. Foreign language teaching means to the introduction of digital processing and display different information forms which is consistent with the process and characteristics of human cognition and thinking that is conducive to improving the efficiency of foreign language teaching in our country, and the teaching form will be modernized and scientific and efficient. But there are still many problems on the digital teaching at present, the equipment management and maintenance of voice room in college are not perfect, so it needs to work with teachers and students and technical personnel. By the good voice room, it is conducive to our foreign language teaching out of the woods avoiding empty talk or dumb English teaching to change English teaching situation, and to achieve the goal of life-long education.

\section{References}

[1] Hang Li. Problems and countermeasures of the construction and management of the foreign language voice room [J]. Journal of Guangxi Teachers Education University, 2004, 04:154-156.

[2] Silian Lin. Problems and countermeasures in the voice room of colleges [J]. Journal of Jiangxi Finance and Staff University, 2009, 04: 139-141.

[3] Lizhi Guo. Problems and countermeasures in the construction of foreign language voice room in colleges-- Department of foreign languages of Hunan Science and Engineering University [J]. Exam Week, 2010, 13: 104-105.

[4] Shuhong Yan. Some experiences in the management of multimedia voice room [J]. Development and Economy of Science and Technology Information, 2008 (12).

[5] Yong Duan. Scientific maintenance and management of foreign language voice room [J].Journal of Taiyuan City Vocational College, 2015, 01: 75-76.

[6] Huining Song, Kai Zhang. Study on management and maintenance of voice room in college [J].Educational Technology and Equipment in China, 2015, 14: 32-34.

[7] Hui Nie. Study on the problems and Countermeasures of multimedia voice room in the foreign language teaching in colleges [J].Higher Education Equipment, 2005(8). 